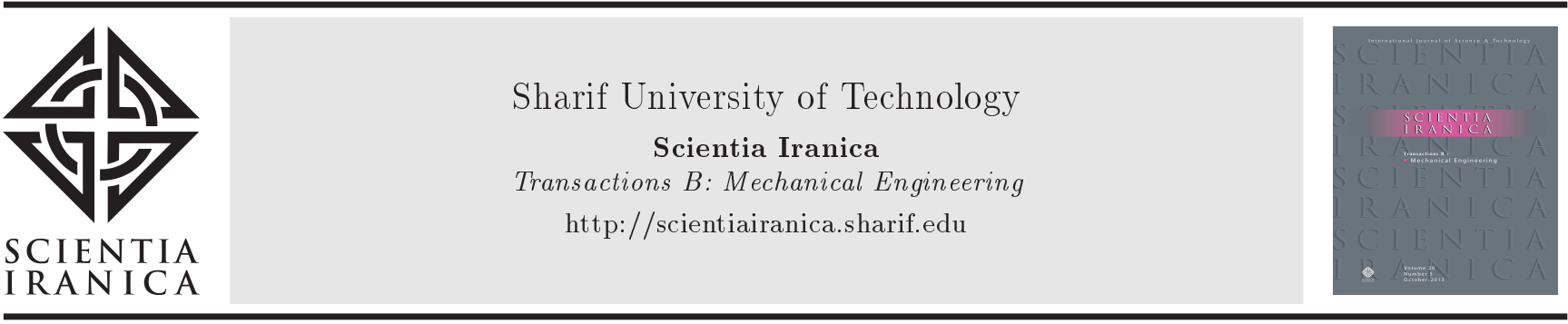

Research Note

\title{
Investigation on the effect of using rubber as core material in sandwich composite plate subjected to low-velocity normal and oblique impact loadings
}

\author{
M. Vishwas*, Sh. Joladarashi, and S.M. Kulkarni \\ Department of Mechanical Engineering, National Institute of Technology Karnataka, Surathkal, Mangalore, 575025, India.
}

Received 8 November 2017; received in revised form 19 November 2017; accepted 2 January 2018

\author{
KEYWORDS \\ Jute epoxy; \\ Low velocity; \\ Oblique impact; \\ Finite Element (FE) \\ simulation; \\ Sandwich composite; \\ Rubber core.
}

\begin{abstract}
In this article, the structural performance of composite plate under lowvelocity impact is studied. Two forms of layup sequence, namely, Jute-Epoxy laminate (JE) and Jute-Epoxy-Rubber sandwich (JE-R-JE), were considered for evaluation. Special emphasis was on evaluating the influence of normal and oblique loadings. Various dynamic parameters, such as energy, peak load, and deformation, were analysed in detail to study the effect of impact angle on both laminate and sandwich structures. Stress analysis of both laminate and sandwich structures was carried out to discuss the effect of introducing rubber as a core material. The results revealed that using rubber as a core material had a significant effect on energy absorption. In addition, it was noticed that increasing the angle of impact would yield better performance of the composite plate. The results presented here may serve as benchmark for effective utilization of composite plates in low-velocity impact applications.
\end{abstract}

C 2019 Sharif University of Technology. All rights reserved.

\section{Introduction}

Nowadays, in the automotive industry, the focus is being shifted towards reducing the weight of the components that indirectly increase the economic burden of fuel consumption. Composites are replacing the conventional metal and alloys in structural and semistructural applications due to their enhanced mechanical properties over conventional materials, like aluminium and steel, with high sp. strength and stiffness combined with better corrosion resistance.

Cladding panels are used to protect some of the primary structures in automobiles. Off road and off highway vehicles need to travel more on the gravel

*. Corresponding author. Tel.: +91-9986644944 E-mail address: vishwasmahesh@gmail.com (M.Vishwas)

doi: $10.24200 /$ sci. 2018.5538 .1331 surfaces. The components like fuel tank located in the bottom portion of such vehicles during their operation may be subjected to impact loading by the gravel or flying debris. The impact caused by flying debris may result in extensive damage to automobile body and its components. Such damage, if caused to the components like fuel tank, may result in leakage of fuel from the tank and, if not noticed, may be a serious threat. In order to protect the components from such impact, the cladding panels may be incorporated, which can resist such impacts and thereby avoid the possible damage.

The study carried out by Shah [1] and Michael et al. [2] showed that reinforcing natural fibers in polymer composites has been practiced commonly over the last decade because of the promising properties like high sp. stiffness and lower environmental impacts they provide. An extensive study by Omar et al. [3] and Libo et al. [4] showed that the natural fibers were considered 
as replacements for manmade glass fibers in structural and semi-structural applications, which are becoming increasingly common in transportation and sport goods industries. For the purpose of absorbing energy during an impact event, polymer matrix composites reinforced with natural fibers were widely studied by Fahmi et al. [5], Andrez et al. [6], and Neng et al. [7].

Natural rubber is a material that is abundantly available in nature and using it as a matrix material provides numerous advantages like low cost, ease of availability, and biodegradability. Stelldinger et al. [8] showed that by integrating the rubber layer in a composite laminate, significant improvement in impact damage resistance could be achieved. Structural or semi-structural components during their operation are subjected to impact loading ranging from low to high velocity. Kabir and Shafei [9] explained that projectile induced impacts could be classified into low and high velocities according to projectile mass and velocity. Regimes of velocity classify any velocity up to $10 \mathrm{~m} / \mathrm{s}$ as low velocity, between $100-1000 \mathrm{~m} / \mathrm{s}$ as high velocity, and greater than $2 \mathrm{~km} / \mathrm{s}$ as hyper velocity. There also exists intermediate velocity between $10-100 \mathrm{~m} / \mathrm{s}$, which is argued by some researchers to belong to low velocity and by some to high velocity. Though many researchers have studied the impact behaviour of composites, it is not still completely comprehended as concluded by Aktay et al. [10] and Brenda et al. [11]. Sjoblom et al. [12] and Shivakumar et al. [13] proposed that low-velocity impact events can occur in the range of $1-10 \mathrm{~m} / \mathrm{s}$ depending on the target stiffness, material properties, and impactor mass as well as its stiffness. They usually occur during manufacturing and maintenance of the structural or semi-structural components due to striking of another part or tool drop, or during operation of the parts, like the striking of gravel or debris, spall from the explosion, etc.

Behavior of composites subjected to normal impact loading has been studied by many researchers. However, in real-life engineering applications, the components are rarely subjected to normal impacts. Instead, they are subjected to oblique impacts. Rebounding of the projectile can occur depending on the angle at which it impacts the structure or target. Sadeghzadeh [14] studied the effect of impact velocity and impact angles on impact dynamics of graphene nano sheets in collision with metallic nano particles. Based on available literature, it is found that there are hardly any studies available on composites fabricated with low-cost naturally available materials subjected to oblique impact loading under low velocity.

Despite abundant work on impact behaviour of composites and other materials, the opportunity of exploring the potentiality of rubber as an energy absorbing material under low-velocity impact is hardly focused upon. The objective of the present study is to investigate the low-velocity normal impact and oblique impact behaviour of Jute-Epoxy laminate (JE) and Jute-Epoxy-Rubber (JE-R-JE) sandwich composites at various oblique angles and normal impact. Yazdani et al. [15] proposed that due to the high cost and time involved in testing, using numerical method was inevitable and since the present study is a preliminary step aimed at exploring the usage of new material for energy absorption application under low-velocity impact, analysis is performed using Finite Element Method (FEM). The study has been carried out for various angles of impact $\left(0^{\circ}, 5^{\circ}, 10^{\circ}, 15^{\circ}\right.$, and $\left.20^{\circ}\right)$.

\section{Validating analysis model and mesh convergence}

This section deals with verifying the methodology adopted for low-velocity impact analysis of composite plates. An example of the study made by Karas [16] is taken as a reference to validate the Finite Element (FE) method employed in the present study. The same methodology was employed by Hyunbum [17] to validate his study on graphite-epoxy composite. To this end, the numerical example considered by Karas [16] is reproduced with the aid of the present methodology.

\subsection{Comparison of analysis results with the study carried out by Karas [16]}

A study of low-velocity impact behaviour on a steel plate of dimensions $0.2 \times 0.2 \times 0.008 \mathrm{~m}$ was carried out by Karas [16], in which the four edges of the plate were fixed and the plate was subjected to impact loading at a velocity of $1 \mathrm{~m} / \mathrm{s}$. The model of the steel plate, the ball used for impacting the plate, and their meshing are shown in Figures 1(a) and 1(b). The 2D shell element and 3D solid element were used to mesh the plate and ball with 11,680 and 850 elements, respectively. In order to carry out the mesh convergence study, three different sizes of $2 \mathrm{~mm}, 1.5 \mathrm{~mm}$, and $1 \mathrm{~mm}$ were chosen for the mesh. Figures 2(a) and 2(b) show the comparison of the results carried out by Karas [16] and the present study with various mesh sizes of $2 \mathrm{~mm}$, $1.5 \mathrm{~mm}$, and $1 \mathrm{~mm}$. It can be concluded by comparing the graphs of contact force and deformation against

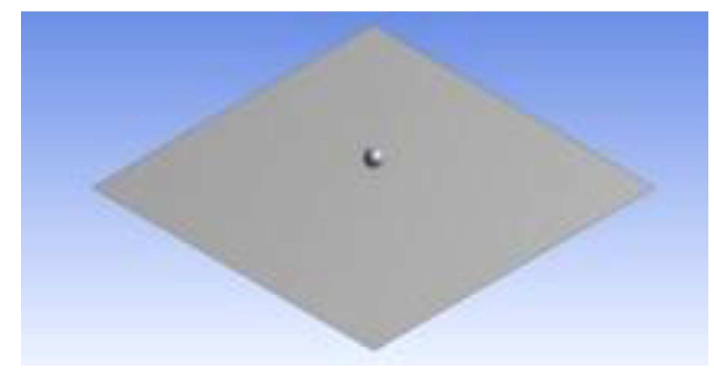

Figure 1(a). Modelling of plate and spherical ball. 


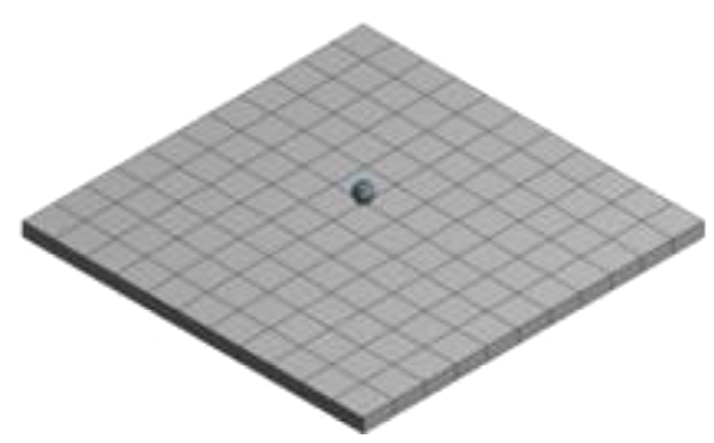

Figure 1(b). Meshing of plate and spherical ball.

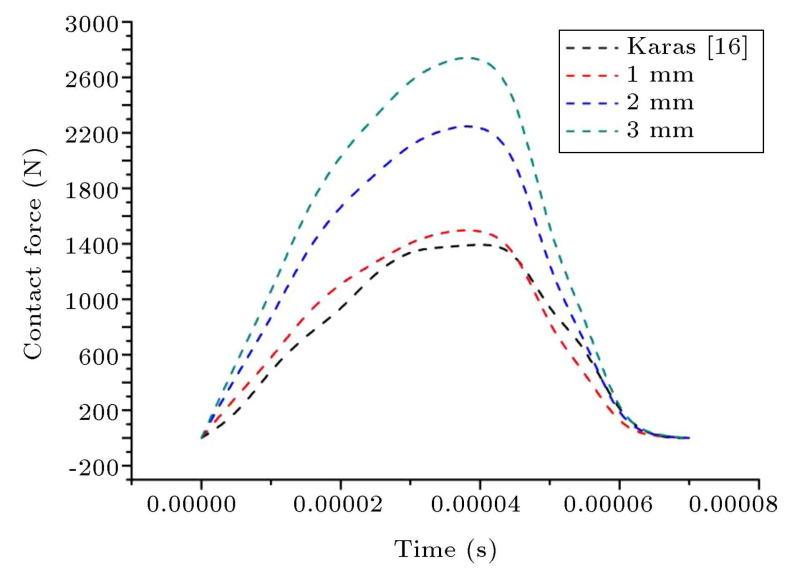

Figure 2(a). Variation of contact force against time [16].

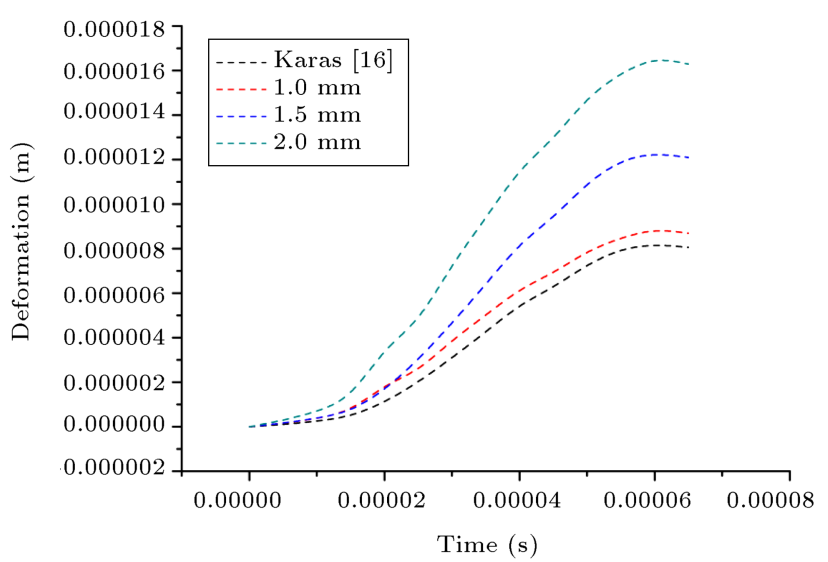

Figure 2(b). Variation of deformation against time [16].

time that the present study closely matches the study conducted by Karas [16] for the mesh size of $1 \mathrm{~mm}$. Hence, the finite element method applied in this study has validity with the mesh size of $1 \mathrm{~mm}$.

\section{Modeling}

The numerical simulation of the present study is carried out using Ansys Workbench commercial software. The procedure adopted in the study of the current modelling has been validated with the procedure provided
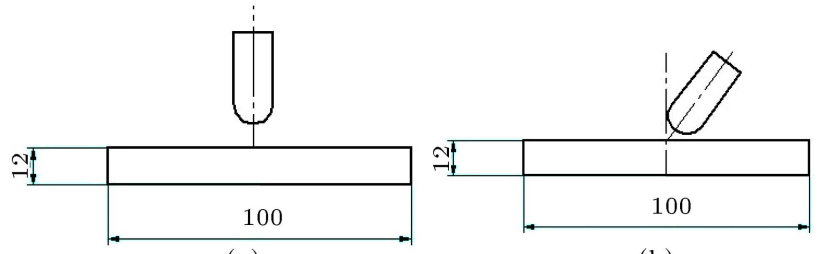

(a)

(b)

Figure 3. Schematic representation of normal (a) and oblique (b) impacts of JE laminate.

by Karas [16] for normal impact loading and the results of oblique impact loading have been compared with those of normal impact loading, as followed earlier by Meybodi et al. [18].

The schematic representations for the normal and oblique impacts of the JE laminate and JE-R-JE sandwich models considered for the present study are provided in Figures 3 and 4, respectively, where all the dimensions represented are in $\mathrm{mm}$. The dimensions of laminate and sandwich are chosen as $100 \mathrm{~mm} \times 150 \mathrm{~mm}$ according to ASTM D7136/D7136M standard. The thickness of the laminate is considered $12 \mathrm{~mm}$, face sheets $3 \mathrm{~mm}$ each, and core $6 \mathrm{~mm}$ in the sandwich. The oblique angle is defined as the angle between axis of the impactor and that normal to the plate.

\subsection{Finite element model}

The meshing details and modelling of JE laminate and JE-R-JE sandwich used for both normal and oblique impact analyses are shown in Figures 5(a)5(e). The size of the element chosen for meshing is $1 \mathrm{~mm}$ with a Quad-type mesh for laminate and sandwich and tetrahedral element for impactor. The mesh convergence study is carried out to ensure the mesh refinement is sufficient to obtain the results with reasonable accuracy. The total number of elements used for laminate and sandwich is 61,056 and for impactor is 1560 . The impactor considered is hemispherical impactor of radius $6.5 \mathrm{~mm}$ made up of steel as in the work carried out by Balasubramani et al. [19].

Figure 6(a) shows the meshing of JE laminate and Figure 6(b) shows the meshing of JE-R-JE sandwich. Figures 6(c) and 6(d) shows the boundary conditions applied to laminate and sandwich along with impactor, respectively. The boundary condition applied to the laminate and sandwich structures is fixed support on the edges of the sandwich structure as well as on the four side faces, and the impactor is given a velocity of $10 \mathrm{~m} / \mathrm{s}$. The model is meshed using shell type element. It is assumed that there is a perfect bonding between face sheet and core, and surface to surface contact relations are defined at the face sheet core interface using contact conditions. During the contact between impactor and sandwich, the friction between impactor and the sandwich is neglected. The impactor is modelled as a rigid body and its motion is governed by 


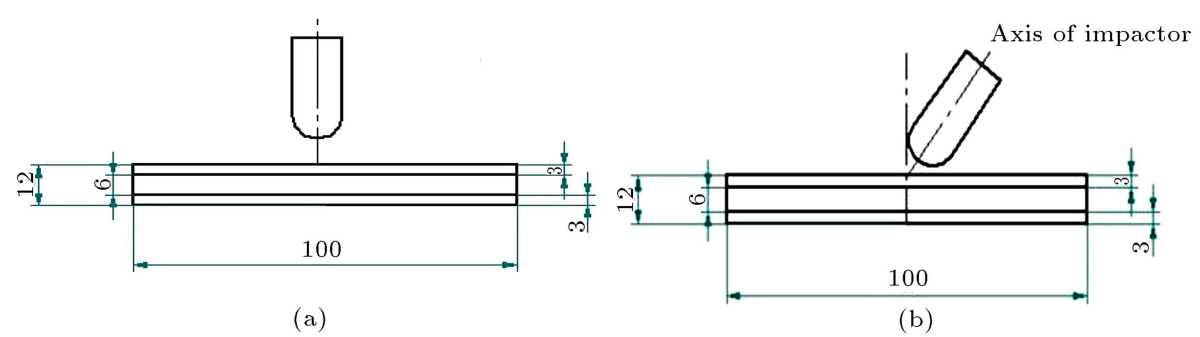

Figure 4. Schematic representation of normal (a) and oblique (b) impacts of JE-R-JE sandwich.

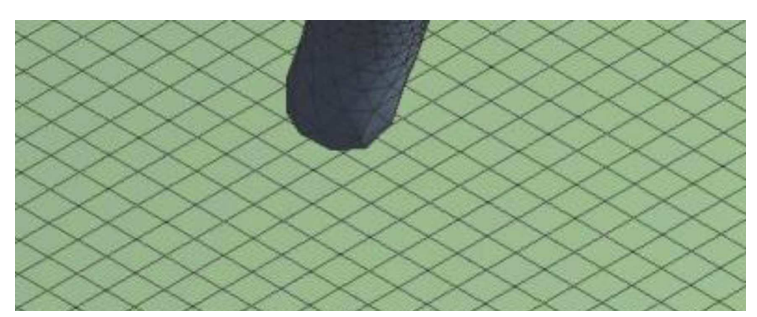

Figure 5(a). Details of meshing used in the present study.

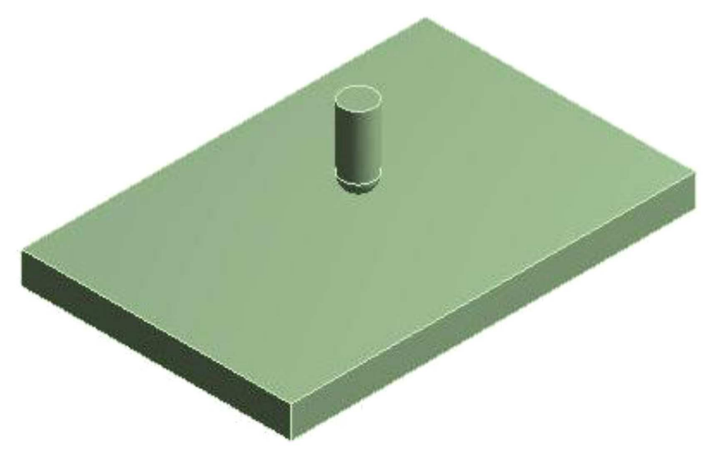

Figure 5(b). Modelling of JE laminate for normal impact.

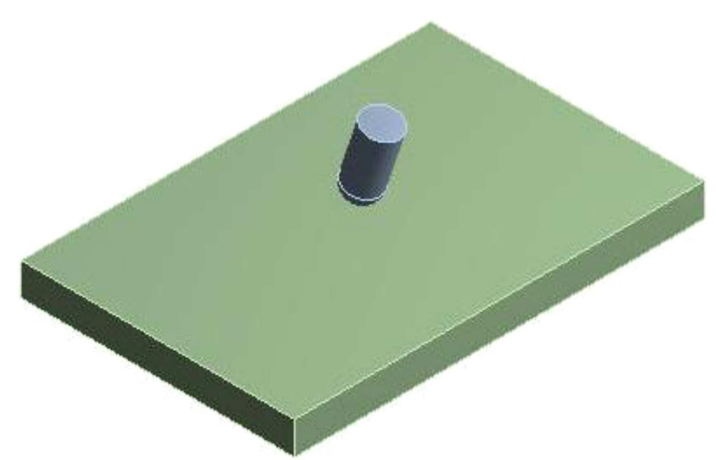

Figure 5(c). Modelling of JE laminate for oblique impact.

the rigid body reference node. The material properties of structural steel used for the impactor and rubber used for core are predefined in commercially available software and given in Table 1. Hashin's failure criterion is used for the purpose of analysis. The initial velocity assigned to the impactor is $10 \mathrm{~m} / \mathrm{s}$ and it is constrained to move only in $Z$ direction. Explicit dynamic analysis

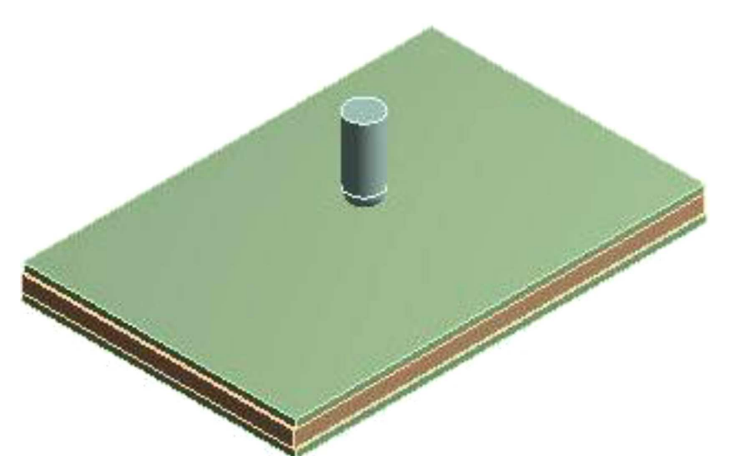

Figure 5(d). Modelling of JE-R-JE sandwich for normal impact.

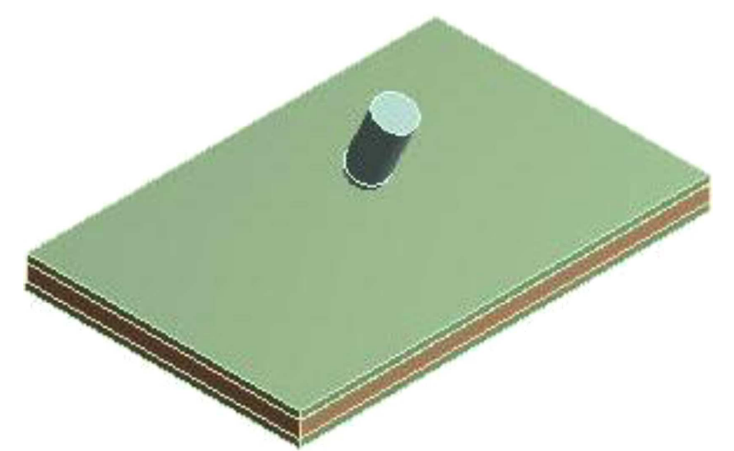

Figure 5(e). Modelling of JE-R-JE sandwich for oblique impact.

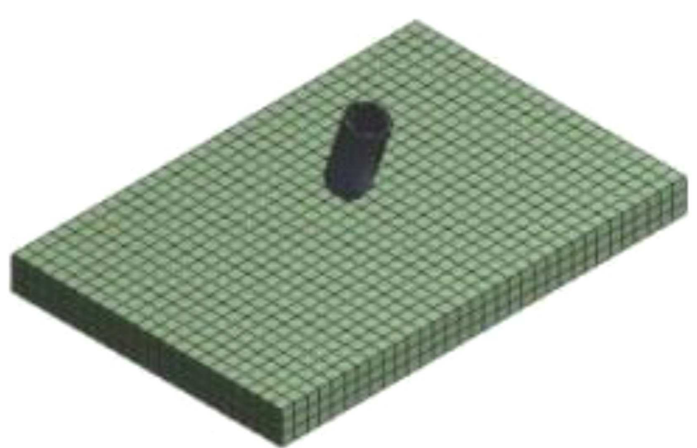

Figure 6(a). Meshing of JE laminate.

type is selected to perform the low-velocity impact test on laminate and sandwich structures. The laminate and sandwich structures are defined as flexible material and impactor as rigid material. Based on the work 


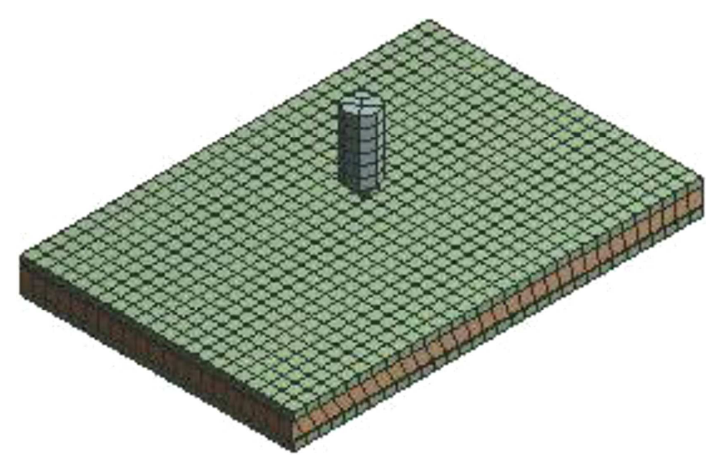

Figure 6(b). Meshing of JE-R-JE sandwich.

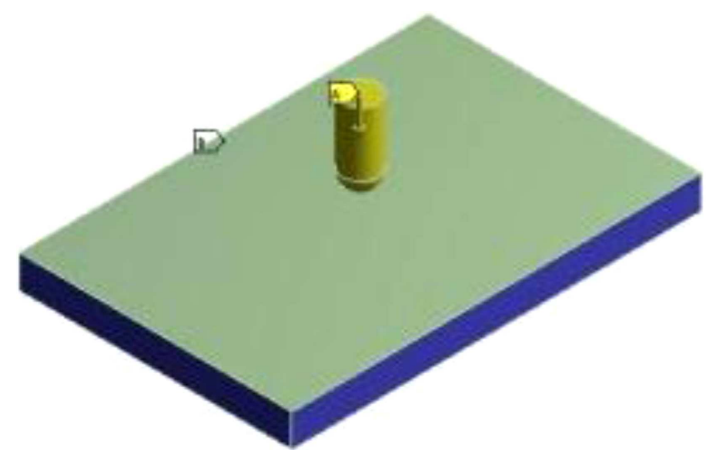

Figure 6(c). Fixed-support boundary condition for JE laminate and velocity boundary condition for impactor.

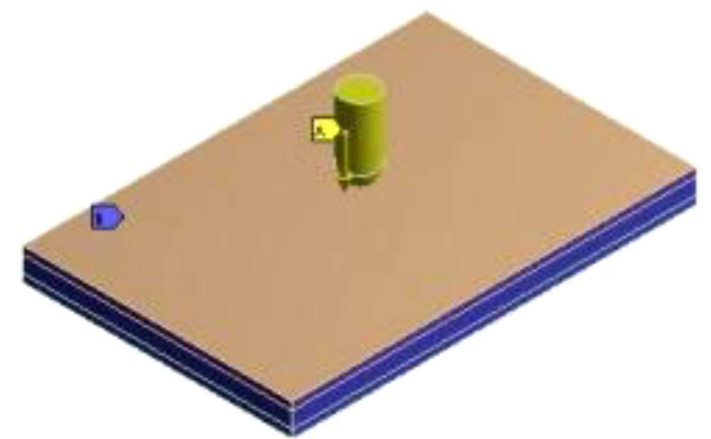

Figure 6(d). Fixed-support boundary condition for JE-R-JE sandwich and velocity boundary condition for impactor.

carried out by Balasubramani et a. [19], Stuart [20], Mir et al. [21], and Hossain et al. [22], the material properties of jute-epoxy used for analysis are drawn and tabulated in Table 2.

\section{Results and discussion}

The current modelling has been validated with the procedure provided by Karas [16] for normal impact loading and the results of oblique impact loading have been compared with those of normal impact loading as followed earlier [18].

\subsection{Contact force}

Peak contact force is of great importance in impact loading as it can control damage initiation. The higher
Table 1. Material properties of structural steel and rubber.

\begin{tabular}{lcc}
\hline \multicolumn{1}{c}{ Properties } & $\begin{array}{c}\text { Structural } \\
\text { steel } \\
\text { (impactor) }\end{array}$ & $\begin{array}{c}\text { Rubber } \\
\text { (core) }\end{array}$ \\
\hline Density $\left(\mathrm{kg} / \mathrm{m}^{3}\right)$ & 7,850 & 1,000 \\
Modulus of elasticity $(\mathrm{MPa})$ & $2,00,000$ & 1 \\
Poisson's ratio & 0.3 & 0.5 \\
Bulk modulus $(\mathrm{MPa})$ & $1,66,600$ & 0 \\
Shear modulus $(\mathrm{MPa})$ & 76,900 & 0.3 \\
Equation of state & Linear & Linear \\
\hline
\end{tabular}

Table 2. Properties of the Jute Epoxy material (JE) [19-22].

\begin{tabular}{lc}
\hline Young's modulus (MPa) & \\
$E_{11}=E_{22}$ & 4,500 \\
$E_{33}$ & 3,200 \\
Shear modulus (MPa) & \\
$G_{12}$ & 1,450 \\
$G_{23}=G_{13}$ & 1,630 \\
Poisson's ratio & \\
$\mu_{12}$ & 0.24 \\
$\mu_{13}=\mu_{23}$ & 0.27 \\
Density (kg/m $\left.{ }^{3}\right)$ & \\
$\rho$ & 1,165 \\
Tensile strength (MPa) & \\
$X_{T}=Y_{T}$ & 104 \\
$Z_{T}$ & 11 \\
Shear strength (MPa) & \\
$S_{12}=S_{13}=S_{23}$ & 23 \\
Compressive strength (MPa) & \\
$X_{C}=Y_{C}$ & 95 \\
$Z_{C}$ & 102 \\
Equation of state & \\
EOS & \\
\hline
\end{tabular}

the peak load, the earlier damage initiation occurs. For all the tested angles $\left(0^{\circ}, 5^{\circ}, 10^{\circ}, 15^{\circ}\right.$, and $\left.20^{\circ}\right)$ on $\mathrm{JE}$ laminate, the graph of contact force as a function of time is shown in Figure $7(\mathrm{a})$ and the same for JE-RJE sandwich is shown in Figure 7(b). All the curves show the same trend where the loading and unloading parts of curve are smooth. The duration in which the impactor is in contact with a sandwich is studied from the graph. Up to the point of initiation of damage or peak load, the variation of force with time is linear. The point where the failure is initiated on the graph is referred to as the maximum load carrying ability. This point was called incipient point of damage by Siow and Shim [23], which is usually a matrix failure. Either the 
Table 3. Contact force variation at various loading conditions.

\begin{tabular}{|c|c|c|c|c|}
\hline \multirow[b]{2}{*}{ Type of loading } & \multicolumn{2}{|c|}{ JE laminate } & \multicolumn{2}{|c|}{ JE-R-JE sandwich } \\
\hline & $\begin{array}{c}\text { Max. contact } \\
\text { force at incipient } \\
\text { point of damage } \\
(\mathrm{N})\end{array}$ & $\begin{array}{c}\text { Peak } \\
\text { contact force } \\
\text { (N) }\end{array}$ & $\begin{array}{c}\text { Max. contact } \\
\text { force at incipient } \\
\text { point of damage } \\
(\mathrm{N})\end{array}$ & $\begin{array}{c}\text { Peak } \\
\text { contact force } \\
\text { (N) }\end{array}$ \\
\hline Normal $\left(0^{\circ}\right)$ & 1865.36 & 2805.31 & 1434.9 & 2157.9 \\
\hline $5^{\circ}$ & 1307.01 & 2281.80 & 1029.1 & 1796.7 \\
\hline $10^{\circ}$ & 929.55 & 1885.74 & 774.6 & 1571.4 \\
\hline $15^{\circ}$ & 770 & 1664.82 & 616 & 1331.9 \\
\hline $20^{\circ}$ & 424 & 1192.09 & 350.4 & 985.2 \\
\hline
\end{tabular}

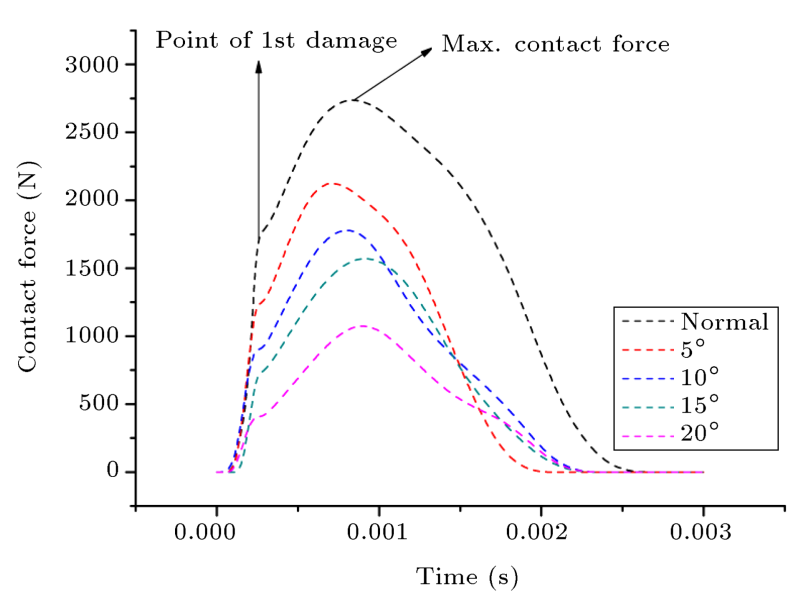

Figure 7(a). Variation of contact force as a function of time for JE laminate.

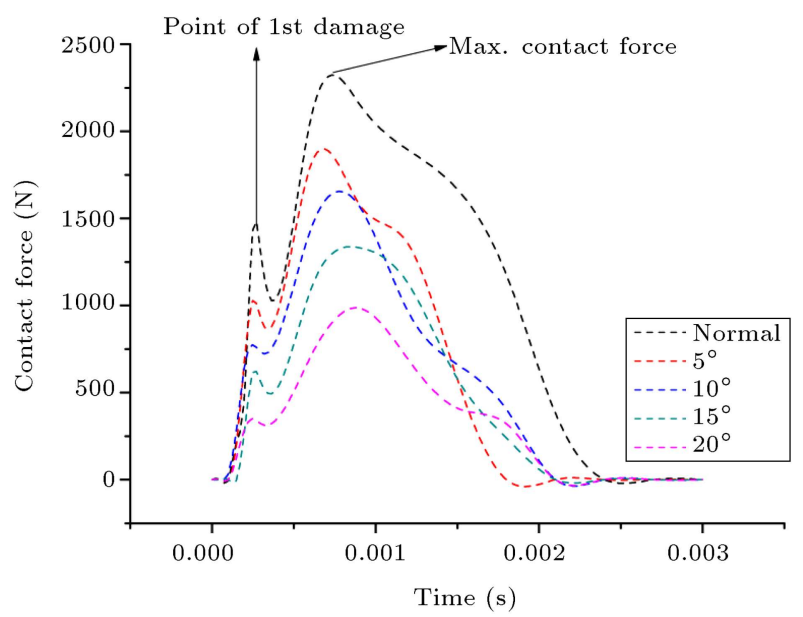

Figure 7(b). Variation of contact force as a function of time for JE-R-JE sandwich.

extent of damage is very small or no visible damage occurs. Therefore, there is a drop in the magnitude of force showing reduction in stiffness of the material. Penetration and perforation damages are the results of a combination of such failures. The peak loads for JE laminate and JE-R-JE sandwich are tabulated in Table 3. The tabulated results show that the peak load will be more in laminate than in sandwich structure for any given case of loading, indicating earlier damage initiation in laminate than in the sandwich. The contact force histories also show that with increase in angle of impact, there is a reduction in peak contact force. The descending part of the unloading is due to continuous loading beyond the peak point where there is a continuous progression of damage to the structure and, thus, a reduction in the contact force. Therefore, the major mode of failure in this impact loading scenario is due to bending stress.

\subsection{Energy}

Gathering knowledge about ability of composite to absorb energy under impact loading is very important and it is the critical parameter studied by most of the researchers. The energy absorbed by the composite is obtained by the difference between initial and final kinetic energy of impactor as given by Eq. (1).

$$
E_{a}=E_{\mathrm{KE}}^{I}-E_{\mathrm{KE}}^{R}
$$

The variation of kinetic energy with respect to time for various loading conditions on JE laminate and JER-JE sandwich is shown in Figures 8(a) and 8(b), respectively. For illustrating the variation of kinetic energy against time during an impact event, the case of normal impact in a laminate is considered. It can be noted from Figure 8(a) that for all types of loading conditions, the kinetic energy of impactor reaches zero at some point of time and after that, it increases. With increase in impact angle, the time at which the kinetic energy becomes zero increases and the residual kinetic energy decreases; hence, residual velocity also decreases. For illustrative purpose, the normal-impact loading case in JE laminate is considered. In stage I, Kinetic Energy (KE) of the impactor drops rapidly after contact with laminate, which is transformed into internal energy of the laminate. At stage II, kinetic energy of the impactor becomes zero at the lowest position. At the same time, Internal Energy (IE) of the laminate becomes the largest. As impact continues, 
Table 4. Kinetic energy and internal energy at different loading conditions for JE laminate.

\begin{tabular}{ccccc}
\hline $\begin{array}{c}\text { Type of loading } \\
\text { on laminate } \\
(\mathbf{J E})\end{array}$ & $\begin{array}{c}\text { Initial } \\
\text { kinetic energy } \\
(\mathbf{J})\end{array}$ & $\begin{array}{c}\text { Residual } \\
\text { kinetic energy }\end{array}$ & $\begin{array}{c}\text { Energy } \\
\text { absorbed } \\
(\mathbf{J})\end{array}$ & $\begin{array}{c}\text { Residual } \\
\text { velocity } \\
(\mathbf{m} / \mathbf{s})\end{array}$ \\
\hline Normal $\left(0^{\circ}\right)$ & & 8.03 & 5.97 & 7.57 \\
$5^{\circ}$ & & 7.95 & 6.05 & 7.53 \\
$10^{\circ}$ & 14 & 7.76 & 6.24 & 7.44 \\
$15^{\circ}$ & & 7.27 & 6.73 & 7.20 \\
$20^{\circ}$ & & 7.12 & 6.88 & 7.13 \\
\hline
\end{tabular}

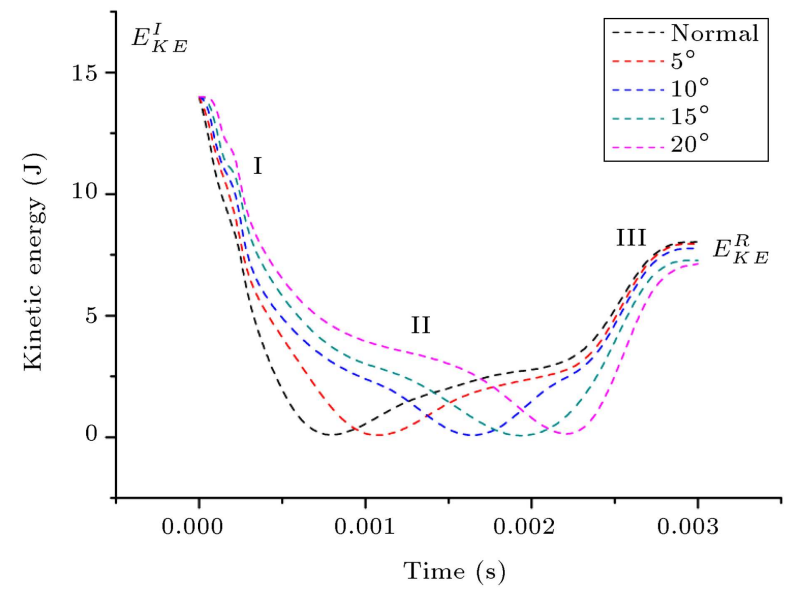

Figure 8(a). Variation of kinetic energy as a function of time for various loading conditions on JE laminate.

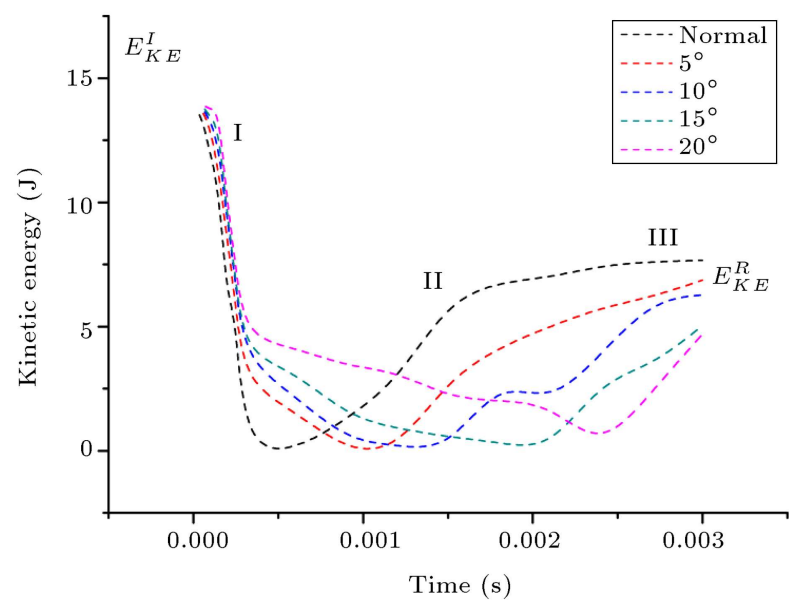

Figure 8(b). Variation of kinetic energy as a function of time for various loading conditions on JE-R-JE sandwich.

kinetic energy of the impactor increases again with rebound of the impactor, which is at stage III. At the end of the impact event, the impactor is separated from the laminate with a constant rebound kinetic energy or residual kinetic energy $E_{\mathrm{KE}}^{R}$. The same concept applies to all the loading conditions in laminate as well as sandwich. The residual velocity of the impactor is calculated using Eq. (2):

$$
V_{R}=\sqrt{\frac{2 E_{\mathrm{KE}}^{R}}{m}},
$$

where $V_{R}$ is residual velocity and $m$ is mass of the impactor in $\mathrm{kg}$. The volume of the impactor is found to be $3.62 \times 10^{-5} \mathrm{~m}^{3}$. Using the volume, according to Eq. (3), the mass of the impactor is calculated as $0.28 \mathrm{~kg}$.

$$
m=\rho \times \operatorname{vol} .
$$

It can be seen from the energy history curve with respect to time that as the impact angle increases, the final energy of impactor, i.e., residual kinetic energy, decreases. This means that the growth of impact angle leads to increase in energy absorption. The initial kinetic energy, residual kinetic energy, residual velocity of the impactor, and the energy absorbed by the laminate are tabulated in Table 4.

The initial kinetic energy, residual kinetic energy, residual velocity of the impactor, and the energy absorbed by the sandwich are tabulated in Table 5. As the angle of impact increases, the residual kinetic energy and residual velocity of impactor decrease and the energy absorbed by laminate and sandwich increases. Thus, it can be concluded that as the impact angle increases, energy absorption increases and JE-R-JE sandwich absorbs more energy than JE laminate does, which can be due to the presence of rubber core that makes the sandwich less brittle than laminate.

\subsection{Total deformation}

Figure 9(a) shows the total deformation against time graph for JE laminate and Figure 9(b) shows the same for JE-R-JE sandwich. Due to the impact at the velocity of $10 \mathrm{~m} / \mathrm{s}$, the maximum deformations obtained in JE laminate are $3.15 \mathrm{~mm}, 2.89 \mathrm{~mm}$, $2.47 \mathrm{~mm}, 2.06 \mathrm{~mm}$, and $1.11 \mathrm{~mm}$, respectively, for normal impact and oblique impact with $5^{\circ}, 10^{\circ}, 15^{\circ}$, and $20^{\circ}$ loadings. For the JE-R-JE sandwich, they are found to be $3.81 \mathrm{~mm}, 3.66 \mathrm{~mm}, 3.35 \mathrm{~mm}, 2.18 \mathrm{~mm}$, and $1.32 \mathrm{~mm}$, respectively. Maximum deformation is observed at the centre of JE laminate and at the centre 
Table 5. Kinetic energy and internal energy at different loading conditions for JE-R-JE sandwich.

\begin{tabular}{ccccc}
\hline $\begin{array}{c}\text { Type of loading on } \\
\text { sandwich structure } \\
\text { (JE-R-JE) }\end{array}$ & $\begin{array}{c}\text { Initial } \\
\text { kinetic energy } \\
(\mathbf{J})\end{array}$ & $\begin{array}{c}\text { Residual } \\
\text { kinetic energy } \\
(\mathbf{J})\end{array}$ & $\begin{array}{c}\text { Energy } \\
\text { absorbed } \\
(\mathbf{J})\end{array}$ & $\begin{array}{c}\text { Residual } \\
\text { velocity } \\
(\mathbf{m} / \mathbf{s})\end{array}$ \\
\hline Normal $\left(0^{\circ}\right)$ & & 7.66 & 6.34 & 7.40 \\
$5^{\circ}$ & \multirow{2}{*}{14} & 6.86 & 7.14 & 7.00 \\
$10^{\circ}$ & & 6.28 & 7.72 & 6.70 \\
$15^{\circ}$ & & 5.04 & 8.96 & 6.00 \\
$20^{\circ}$ & & 4.70 & 9.30 & 5.80 \\
\hline
\end{tabular}

Table 6. Total deformation in various loading conditions for JE laminate and JE-R-JE sandwich.

\begin{tabular}{lccccc}
\hline Total deformation $(\mathbf{m m})$ & Normal $\left(\mathbf{0}^{\circ}\right)$ & $\mathbf{5}^{\circ}$ & $\mathbf{1 0}^{\circ}$ & $\mathbf{1 5}^{\circ}$ & $\mathbf{2 0}^{\circ}$ \\
\hline JE Laminate $(\mathrm{mm})$ & 3.15 & 2.89 & 2.47 & 2.06 & 1.11 \\
JE-R-JE Sandwich $(\mathrm{mm})$ & 3.81 & 3.66 & 3.35 & 2.18 & 1.32 \\
\hline
\end{tabular}

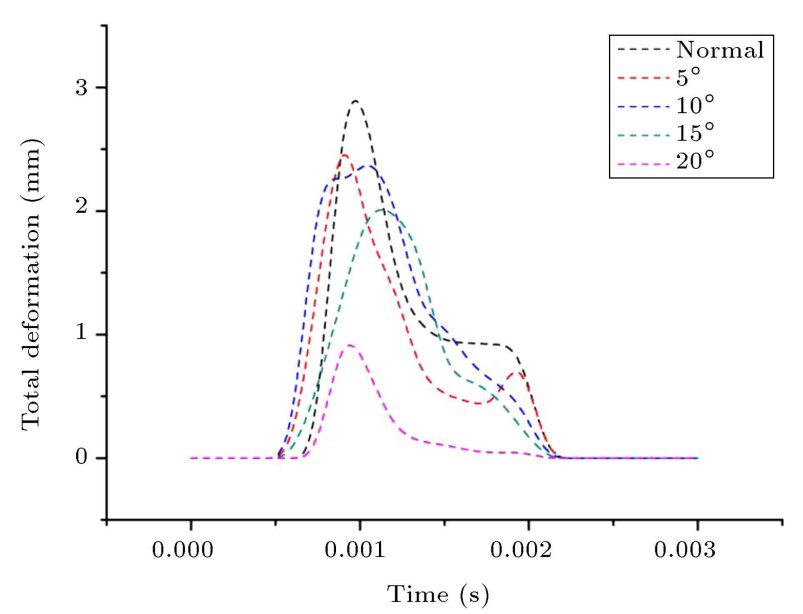

Figure 9(a). Variation of total deformation as a function of time for JE laminate.

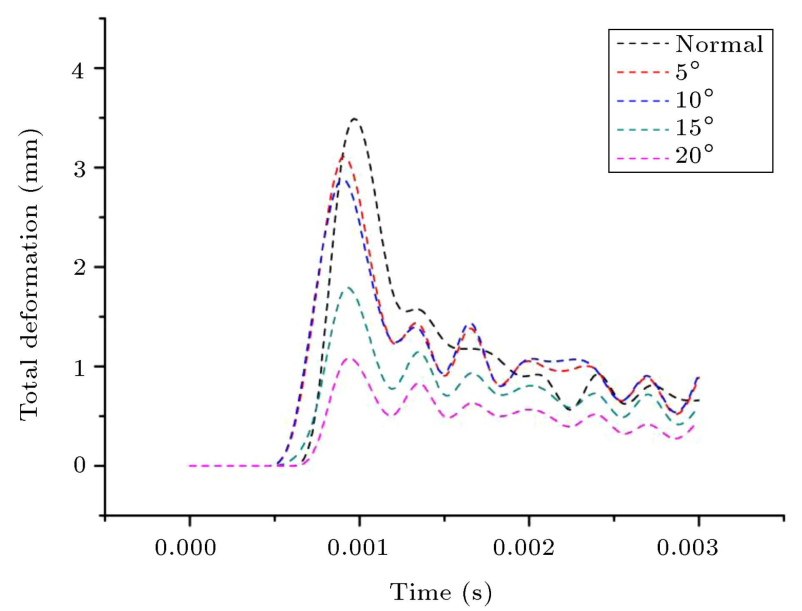

Figure 9(b). Variation of total deformation as a function of time for JE-R-JE sandwich.

of the top face sheet, and minimum deformation at the edges as the four side faces of the sandwich are constrained in all the cases. The maximum deflections of sandwich occur when the impact force becomes equal to zero. During the impact event, the travelling of the impacted surface is indicated by the displacement. Since drop height of the impactor is the same in all the cases, the amount of energy it delivers to the laminate and sandwich will be the same according to Remennikov et al. [24]. The laminate or sandwich which can resist maximum load will undergo the least displacement as load and displacement depends on the amount of energy dissipated by sandwich. It can be concluded from Table 6 that as the oblique angle under consideration increases, the deformation is reduced. Sandwich and laminate at $20^{\circ}$ loading condition can take more load than those at normal loading condition.

\subsection{Stress analysis}

The stress profiles leading to damage in both JE laminate and JE-R-JE sandwich subjected to normal and various oblique impact loading conditions are shown in Figure 10. In case of JE laminate, the occurrence of damage is observed in both top and bottom faces. It can also be seen that as the angle of incidence with respect to the normal one increases, the bands of damage are reduced, indicating that the intensity of damage is being reduced and damage is passed to the bottom surface of laminate due to the brittleness of the JE laminate. This is schematically represented in Figure 11(a).

By comparing the stress patterns under different loading conditions, it can be concluded that there is not much difference between the nature of damages in normal impact and oblique impact with $5^{\circ}$ impact angle. With further increase in the oblique angle, it can be seen that damage zone 2 appears, because the effect of zone 1 gradually decreases and moves away from zone 1 . The size of damage zone 2 becomes gradually smaller with increase in oblique angle due to the reduced intensity of the load. For oblique impact at 


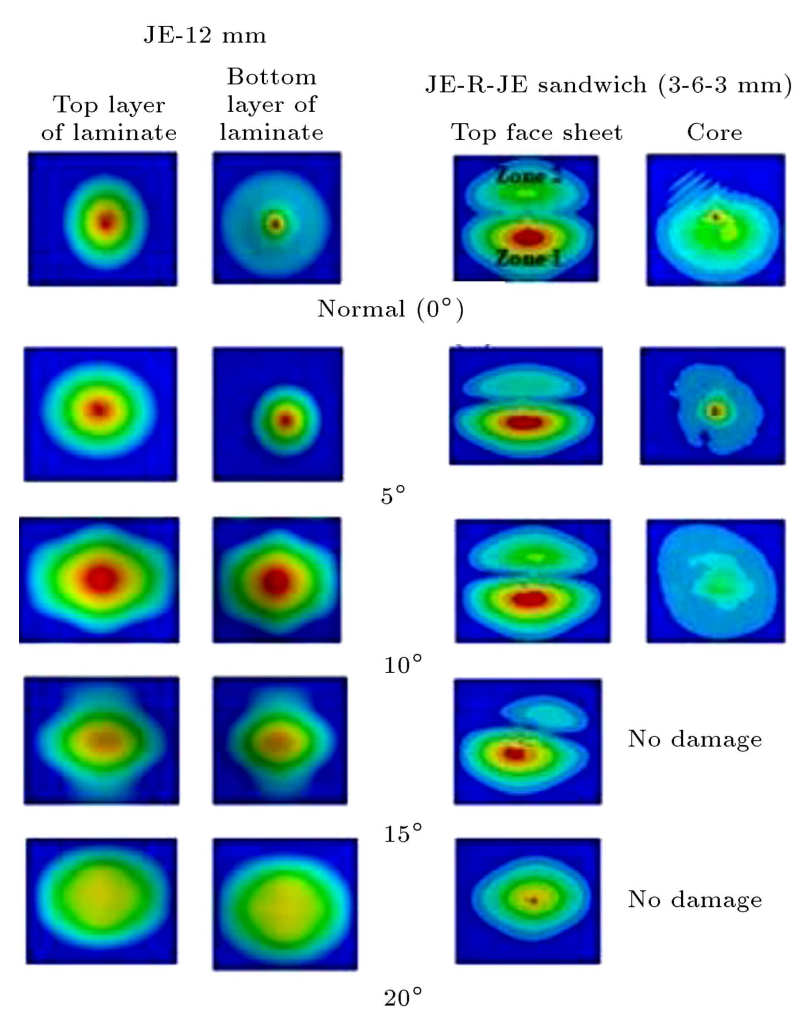

Figure 10. Stress pattern in JE laminate for various loading conditions.

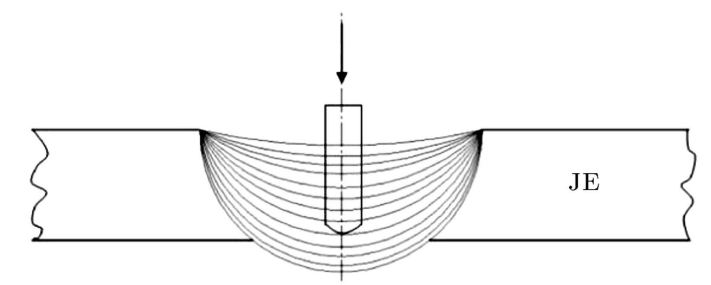

Figure 11(a). Schematic representation of damage progression in JE laminate.

$20^{\circ}$, it can be seen that zone 2 has completely vanished and only zone 1 exists.

In case of JE-R-JE sandwich, the top face sheet is damaged under all types of impact loading. The damage on the top surface of the core is observed only in normal, $5^{\circ}$-, and $10^{\circ}$-degree impact loading conditions, whereas the bottom face sheet is unaffected in all the cases. This can be due to the presence of rubber core. The elastic recovery nature of rubber arrests the strain energy, resulting in prevention of damage to proceed further. This is schematically represented in Figure 11(b). Also, in JE-R-JE sandwich, two zones of damage are observed, namely, zone 1 , which is the primary zone of damage, and zone 2, which is the secondary zone of damage. The secondary zone of damage is gradually reduced as the angle of incidence of impact increases. Also, the intensity of damage decreases. When the damage pattern in JE laminate is compared with that in JE-R-JE sandwich,

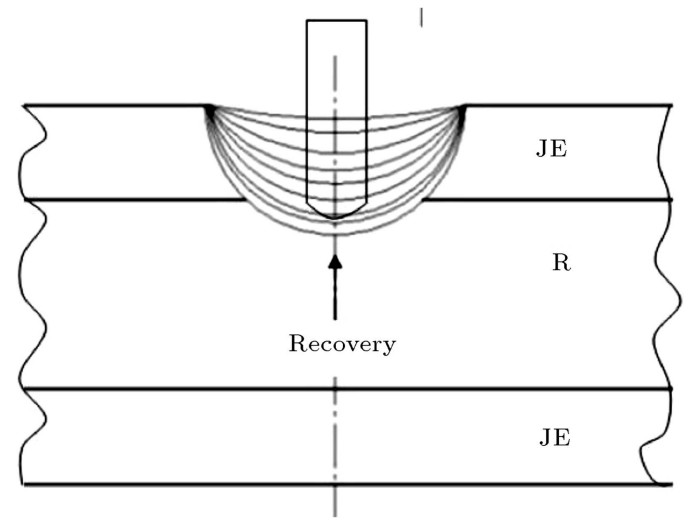

Figure 11(b). Schematic representation of damage progression in JE- R-JE sandwich.

it can be concluded that the damage in the sandwich is less than in the laminate of the same thickness. The presence of rubber as a core material, which is elastic in nature, is the reason. This argument is supported by comparing the absorbed energy of laminate and sandwich in Tables 4 and 5 . The results tabulated in Table 5 show that sandwich deforms more than laminate, which means that sandwich absorbs more energy than laminate.

\section{Conclusions}

In this study, low-velocity impact response under normal and oblique impact loadings for JE laminate and JE-R-JE sandwich composites was investigated with four different oblique angles of $5^{\circ}, 10^{\circ}, 15^{\circ}$, and $20^{\circ}$. The sandwich composite plate was consisted of two jute/epoxy face sheets with the rubber core material. The FE analysis was carried out to analyse the effect of impact angle on the crucial impact parameters, namely, energy, contact force, deformation, and stress patterns. Peak contact load was more in laminate than in sandwich structure for any given case of loading, indicating earlier damage initiation in laminate than in the sandwich. The contact force histories also showed that with increase in impact angle, the peak contact force would decrease. The force at which the point of the first damage appeared was approximately $30 \%$ more in case of JE laminate than in JE-R-JE sandwich under normal loading condition. In case of oblique loading, it was $27 \%$ more for $5^{\circ}, 20 \%$ more for $10^{\circ}$, $25 \%$ more for $15^{\circ}$, and $21 \%$ more for $20^{\circ}$ oblique impact loadings. It could be concluded from the energy history curve with respect to time that as the impact angle increased, the final energy of impactor, i.e., residual kinetic energy and residual velocity, decreased. This means that the growth of impact angle led to increase in energy absorption. JE-R-JE sandwich absorbed more energy than JE laminate did, which could be due to the presence of rubber core that made the sandwich less 
brittle than laminate. The JE-R-JE sandwich absorbed $6.2 \%$ more energy than JE laminate did during normal impact and this drastically increased to $18 \%$ for $5^{\circ}$, $23 \%$ for $10^{\circ}, 33 \%$ for $15^{\circ}$, and $35 \%$ for $20^{\circ}$ oblique impact loadings. From the total deformation plot, it could be concluded that as the impact angle increased, the total deformation decreased, which means the laminate or sandwich with the highest impact angle of loading resisted maximum load. Also, when we compare laminate with sandwich, it can be concluded that sandwich absorbs more energy than laminate does in similar loading conditions. With the same thickness, it can be concluded that the damage caused in the sandwich is less than that in the laminate. The presence of rubber as a core material prevents further progression of damage. This can be due to the elastic nature of rubber. It can also be concluded that the damage caused during normal impact is more than that during oblique impact.

\section{References}

1. Shah, D.U. "Natural fibre composites: Comprehensive Ashby-type materials selection charts", Mater. Des., 62, pp. 21-31 (2014).

2. Michael, P.M.D., Peter, F.D., Anna, B.B., Guillaume, F., Mark, K.H., and Paul, M.W. "Green composites: a review of material attributes and complementary applications", Compos. Part Appl. Sci. Manuf., 56, pp. 280-289 (2014).

3. Faruk, O., Bledzki, A.K., Fink, H.P., and Sain, M. "Biocomposites reinforced with natural fibers: 20002010", Prog. Polym. Sci., 37(11), pp. 1552-1596 (2012).

4. Yan, L., Chouw, N., and Jayaraman, K. "Flax fibre and its composites-a review", Compos. Part B Eng., 56, pp. 296-317 (2014).

5. Fahmi, I., Abdul Majid, M.S., Afendi, M., Helmi, E.A., and M Haameem, J.A. "Low-velocity impact responses of napier fibre/polyester composites", Int. J. of Automot. Mech. Eng., 13(1), pp. 3226-3237 (2016).

6. Andrzej, K.B., Jochen, G., and Wenyang, Z. "Impact properties of natural fiber-reinforced epoxy foams", $J$. Cell. Plast., 35(6), pp. 550-562 (1999).

7. Suharty, N.S., Ismail, H., Diharjo, K., Handayani, D.S., and Firdaus, M. "Effect of kenaf fiber as a reinforcement on the tensile, flexural strength and impact toughness properties of recycled polypropylene/halloysite composites", Procedia Chem., 19, pp. 253-258 (2016).

8. Stelldinger, E., Kuhhorn, A., and Kober, M. "Experimental evaluation of the low-velocity impact damage resistance of CFRP tubes with integrated rubber layer", Compos. Struct., 139, pp. 30-35 (2016).

9. Kabir, M.Z. and Shafei, E. "Analytical and numerical study of FRP retrofitted RC beams under low velocity impact", Sci. Iran. Trans. A, 16(5), pp. 415-428 (2009).

10. Aktay, L., Johnson, A.F., and Holzapfel, M. "Prediction of impact damage on sandwich composite panels", Comput. Mater. Sci., 32(3-4), pp. 252-260 (2005).

11. Brenda, L.B., Carlos, S., Sonia, S., Enrique, B., and Carlos, N. "Modelling of composite sandwich structures with honeycomb core subjected to highvelocity impact", Compos. Struct., 92(9), pp. 20902096 (2010).

12. Sjoblom, P.O., Hartness, J.T., and Cordell, T.M. "On low velocity impact testing of composite materials", $J$. Compos. Mater., 22(1), pp. 30-52 (1998).

13. Shivakumar, K.N., Elber, W., and Illg, W. "Prediction of low velocity impact damage in thin circular laminates", AIA A J., 23(3), pp. $442-449$ (1985).

14. Sadeghzadeh, S. "Impact dynamics of graphene nanosheets in collision with metallic nanoparticles", Sci. Iran. Trans. F, 23(6), pp. 3153-3162 (2016).

15. Yazdani Ariatapeh, M., Mashayekhi, M., and ZiaeiRad, S. "Prediction of all-steel CNG cylinder fracture under impact using a damage mechanics approach", Sci. Iran. Trans. B, 21(3), pp. 609-619 (2014)

16. Karas, K. "Plates under lateral impact", Arch. Appl. Mech., 10, pp. 237-250 (1939).

17. Hyunbum, P. "Investigation on low velocity impact behavior between graphite/epoxy composite and steel plate", Compos. Struct., 171, pp. 126-130 (2017).

18. Meybodi, M.H., Mohammadkhani, H., and Bagheri, M.R. "Oblique low-velocity impact on fiber-metal laminates", Appl. Compos. Mater., 24(3), pp. 611-623 (2016).

19. Balasubramani, V., Rajendra Boopathy, S., and Vasudevan, R. "Numerical analysis of low velocity impact on laminated composite plates", Procedia Eng., 64, pp. 1089-1098 (2013).

20. Stuart, M. Lee., Handbook of Composite Reinforcement, Wiley Publications, Palo Alto, California, USA (1992).

21. Mir, A., Aribi, C., and Bezzazi, B. "Study of the green composite jute/epoxy", IJMME, 8(2), pp. 182186 (2014).

22. Hossain, M.R., Islam, M.A., Vuurea, A.V., and Verpoest, I. "Effect of fiber orientation on the tensile properties of jute epoxy laminated composite", JSR, 5(1), pp. 43-54 (2013).

23. Siow, Y.P. and Shim, V.P.W. "An experimental study of low velocity impact damage in woven fibre composites", J. Compos. Mater., 32(12) pp. 1178-1202 (1998).

24. Remennikov, A.M., Kong, S.Y., and Uy, B. "Response of foam- and concrete-filled square steel tubes under low-velocity impact loading", J. Perform. Constr. Fac., 25(5), pp. 373-381 (2011). 


\section{Biographies}

Mahesh Vishwas received his BE degree in Mechanical Engineering and M.Tech degree in Product Design and Manufacturing in 2007 and 2011, respectively, from Visvesvaraya Technological University, Belagavi, Karnataka, India. He is currently working as research scholar in the Department of Mechanical Engineering, National Institute of Technology Karnataka, Surathkal, Mangalore, India. His research interests include composite materials and impact dynamics. He has published and presented many papers in international journals and conferences.

Sharnappa Joladarashi received his BE degree in Mechanical Engineering and ME degree in Advanced Manufacturing Engineering in 2000 and 2003 from Gulbarga University, Karnataka, India, and National Institute of Technology Karnataka, Surathkal, respectively. He has also received his $\mathrm{PhD}$ degree from Indian Institute of Technology Madras (IIT-M) in
2008. He is currently working as Assistant Professor in the Department of Mechanical Engineering, National Institute of Technology Karnataka, Surathkal, Mangalore, India. His research interests include composite materials. He has published and presented many papers in international journals and conferences.

Satyabodh M Kulkarni received his BE degree and ME degree in Mechanical Engineering in 1985 and 1989 from Mysore University, Karnataka, India, and Bharthiar University, Tamilnadu, India, respectively. He has also received his $\mathrm{PhD}$ degree from Indian Institute of Science Bangalore (IISc) in 2002. He is currently working as Professor in the Department of Mechanical Engineering, National Institute of Technology Karnataka, Surathkal, Mangalore, India. His research interests include composite materials and MEMS. He has published and presented many papers in international journals and conferences, and authored many book chapters. 